\title{
Canadian Association of Emergency Physicians Sepsis Guidelines: the optimal management of severe sepsis in Canadian emergency departments
}

\author{
Robert S. Green, BSc, MD; ${ }^{*}$ Dennis Djogovic, MD; ${ }^{\dagger}$ Sara Gray, MD, MPH; $;$ Daniel Howes, MD; ${ }^{\S}$ \\ Peter G. Brindley, MD; ${ }^{\dagger}$ Robert Stenstrom, MD, PhD; ${ }^{; l}$ Edward Patterson, MD; ${ }^{* *}$ David Easton, MD; ${ }^{\dagger \dagger}$ \\ Jonathan S. Davidow, MD; ${ }^{\dagger}$ on behalf of the CAEP Critical Care Interest Group (C4)
}

See related article on page 461

UNE VERSION FRANÇAISE SERA PUBLIÉE

DANS LE NUMÉRo DE NOVEMBRE 2008

\begin{abstract}
Introduction: Optimal management of severe sepsis in the ED has evolved rapidly. The purpose of these guidelines is to review key management principles for Canadian emergency physicians, utilizing an evidence-based grading system.

Methods: Key areas in the management of septic patents were determined by members of the CAEP Critical Care Interest Group (C4). Members of C4 were assigned a question to be answered after literature review, based on the Oxford grading system. After completion, each section underwent a secondary review by another member of C4. A tertiary review was conducted by additional external experts, and modifications were determined by consensus. Grading was based on peer-reviewed publications only, and where evidence was insufficient to address an important topic, a "practice point" was provided based on group opinion.

Results: The project was initiated in 2005 and completed in December 2007. Key areas which were reviewed include the definition of sepsis, the use of invasive procedures, fluid resuscitation, vasopressor/inotrope use, the importance of culture acquisition in the ED, antimicrobial therapy and source control. Other areas reviewed included the use of corticosteroids, activated protein $C$, transfusions and mechanical ventilation.

Conclusion: Early sepsis management in the ED is paramount for optimal patient outcomes. The CAEP Critical Care Interest Group Sepsis Position Statement provides a framework to improve the ED care of this patient population.
\end{abstract}

Keywords: sepsis, severe sepsis, septic shock, emergency medicine, guidelines, resuscitation

\section{Introduction}

The management of sepsis has recently attracted longoverdue attention. Evidence supports the need for rapid identification and initiation of treatment in patients with severe sepsis. Given the widespread incidence, cost and mortality of sepsis, and because it affects patients with numerous medical and surgical comorbidities, optimal sepsis manage-

From the *Department of Emergency Medicine and the Division of Critical Care Medicine, Department of Internal Medicine, Dalhousie University, Halifax, NS, the †Department of Emergency Medicine, University of Alberta, Edmonton, Alta., the ¥Division of Emergency Medicine, University of Toronto, and Emergency Medicine \& Intensive Care Medicine, St. Michael's Hospital, Toronto, Ont., §Emergency Medicine and Critical Care, Queen's University, and the Department of Emergency Medicine, Kingston General Hospital, Kingston, Ont., Providence Health Care and the Department of Emergency Medicine, St. Paul's Hospital, Vancouver, BC, the **Departments of Internal Medicine and Emergency Medicine, Regina Qu'Appelle Health Region and the University of Saskatchewan, Regina, Sask., and the t†Department of Emergency Medicine, Health Sciences Centre, Winnipeg, Man.

CAEP Board approved June 11, 2008

CJEM 2008;10(5):443-59 
ment is germane to many medical practitioners. However, emergency medicine (EM) physicians are in a unique position to have a significant impact on patient outcome.

Although sepsis guidelines have been previously published, there has been little focus on patients who present to the emergency department (ED) or on the Canadian health care system. Therefore, the Canadian Association of Emergency Physicians (CAEP) Critical Care Interest Group (C4) initiated this project in 2005. The goal was to provide concise, up-to-date, evidence-based guidelines for optimal sepsis management in adult patients, focusing on issues that are relevant to Canadian EM. The $\mathrm{C} 4$ members possess expertise in EM, critical care medicine or both. The $\mathrm{C} 4$ chair determined "relevant questions" to be "areas of importance for the management of severe sepsis in Canadian EM practice." An initial PubMed search was completed by the chair using the terms "sepsis," "severe sepsis," "septic shock," "diagnosis," "treatment" and "therapy," and a reference list was made available to $\mathrm{C} 4$ members using a secure Web-based portal (hosted by the Department of Emergency Medicine, Dalhousie University, Halifax, NS). Members were encouraged to perform additional literature searches in order to ensure all relevant studies were considered. In addition, members were instructed to provide objective recommendations to each question based on the quality of available evidence (Table 1, Table 2), using the Oxford Level of Evidence Grading System. ${ }^{1}$ Individual sections were combined by the chair, and a secondary review of each section was completed by $\mathrm{C} 4$ members. A tertiary review was completed by the entire group, and all recommendations were finalized by group consensus. An additional review was also completed by external reviewers with expertise in sepsis. The guideline is presented in sections: "Questions," "Practice points," "Recommendations" and "Rationale." The authors have attempted to base opinions on current, peer-reviewed publications. No funding from any source other than CAEP for conference calls was used for the creation of this document. Areas that objective data do not sufficiently address, yet were considered essential for optimal care in Canadian EM practice by $\mathrm{C} 4$, are presented as "Practice points."

The authors recognize that the management of sepsis is challenging and have strived to outline complex concepts in a straightforward manner that is relevant to all Canadian EM physicians, nurses and other personnel who provide care in the ED. However, the management of sepsis will continue to evolve. As such, we anticipate that our current guidelines will require modification in the future. In addition, in order to achieve improved patient outcomes, care providers require more than knowledge of evidence-based treatments. Other key determinants include practitioner skill, adequate resources and the creation of systems that promote seamless multidisciplinary care across the continuum, from prehospital to the ED to the intensive care unit (ICU). C4 strongly encourages physicians in each ED to address the translation of evidence at a local level, where they are, after all, the experts.

\section{A. Sepsis and emergency medicine}

\section{Questions}

1. What is the morbidity and mortality associated with severe sepsis?

2. Why is EM important in diagnosing and managing patients with sepsis?

\section{Practice point}

Severe sepsis and septic shock are common in the ED and have an associated mortality of 20\%-50\%. EM physicians are in a unique position to recognize and institute treatments that optimize patient outcomes.

\section{Rationale}

Sepsis and septic shock are common presentations to the ED and challenge medical staff on a daily basis. ${ }^{2}$ In the United States, 660000 to 750000 cases of sepsis are estimated to occur per year with a mortality rate of approximately 20\%-50\%., ${ }^{3,4}$ The incidence of sepsis has increased by $8.7 \%$ per year in the last 20 years and, despite evidence that mortality rates are improving, the total number of deaths per year are increasing. ${ }^{3}$ In addition, patients who survive report a substantial reduction in their quality of life. ${ }^{3}$

Emergency physicians are required to diagnose and manage a broad range of complaints, from those that are relatively minor in nature to those that are life-threatening. Unfortunately, the incidence of critically ill patients presenting to the ED is increasing. ${ }^{5-7}$ In addition, these patients are managed in the ED for prolonged periods of time, ${ }^{7-10}$ requiring emergency physicians to possess the knowledge and skills to effectively provide ongoing care.

Various disease states, including sepsis, have decreased morbidity and mortality as a result of early diagnosis and management. The initial hours of care for trauma patients, ${ }^{11}$ septic patients, ${ }^{12}$ myocardial infarction patients ${ }^{13}$ and stroke patients ${ }^{14}$ are critical to their long-term outcomes.

Severe sepsis and septic shock require comprehensive, aggressive and time-dependent resuscitation in the ED. Recent literature has demonstrated multiple novel options for the management of severe sepsis and septic shock. ${ }^{12,15-17}$ In one study, early and aggressive resuscitation of severely septic patients in the ED resulted in a substantial improve- 
ment on mortality. ${ }^{12}$ Others have demonstrated increased mortality after inappropriate antimicrobial therapy selection and delay in administration. ${ }^{18-21}$ As such, the clinical management of severe sepsis and septic shock has evolved dramatically. Specific therapeutic options should be instituted in the ED to provide a morbidity and mortality benefit.

\section{B. Definition of sepsis}

\section{Questions}

1. How is sepsis defined?

2. What is the difference between sepsis, severe sepsis and septic shock?

3. What are the clinical manifestations of severe sepsis and septic shock?

\section{Practice point}

Sepsis is defined as the presence of both systemic inflam- matory response syndrome and the suspicion of an infection. Sepsis is a syndrome, and can range from relatively mild (simple infection) to severe (septic shock and multiorgan dysfunction). Morbidity and mortality increase if a patient deteriorates from sepsis to severe sepsis to multiorgan dysfunction.

\section{Rationale}

Sepsis is a complex syndrome in which the clinical presentation can overlap with many other disease states. Simple bedside tests, such as serum troponins in acute myocardial infarction or bedside ultrasounds for intra-abdominal fluid, are not available. Clinicians rely on the patient history, physical exam and nonspecific laboratory investigations to diagnosis sepsis.

Sepsis has been defined as the presence, or suspicion of, an infection, in addition to evidence of increased levels of circulating inflammatory mediators, thus resulting in the

Table 1. Oxford Centre for Evidence-based Medicine Levels of Evidence (May 2001) (Part 1 of 2)

\begin{tabular}{|c|c|c|c|c|c|}
\hline Level & $\begin{array}{c}\text { Therapy/prevention, } \\
\text { etiology/harm }\end{array}$ & Prognosis & Diagnosis & $\begin{array}{l}\text { Differential } \\
\text { diagnosis/symptom } \\
\text { prevalence study }\end{array}$ & $\begin{array}{c}\text { Economic and decision } \\
\text { analyses }\end{array}$ \\
\hline $1 a$ & $\begin{array}{l}\text { SR (with } \\
\text { homogeneity*) of } \\
\text { RCTs }\end{array}$ & $\begin{array}{l}\text { SR (with } \\
\text { homogeneity*) of } \\
\text { inception cohort } \\
\text { studies; CDRt } \\
\text { validated in different } \\
\text { populations }\end{array}$ & $\begin{array}{l}\text { SR (with homogeneity*) } \\
\text { of Level } 1 \text { diagnostic } \\
\text { studies; CDRt with } 1 \mathrm{~b} \\
\text { studies from different } \\
\text { clinical centres }\end{array}$ & $\begin{array}{l}\text { SR (with } \\
\text { homogeneity*) of } \\
\text { prospective } \\
\text { cohort studies }\end{array}$ & $\begin{array}{l}\text { SR (with homogeneity*) of } \\
\text { Level } 1 \text { economic studies }\end{array}$ \\
\hline $1 b$ & $\begin{array}{l}\text { Individual RCT (with } \\
\text { narrow confidence } \\
\text { interval } \neq \text { ) }\end{array}$ & $\begin{array}{l}\text { Individual inception } \\
\text { cohort study with } \\
\geq 80 \% \text { follow-up; } \\
\text { CDR† validated in a } \\
\text { single population }\end{array}$ & $\begin{array}{l}\text { Validating** cohort } \\
\text { study with goodtt† } \\
\text { reference standards; or } \\
\text { CDRt tested within one } \\
\text { clinical centre }\end{array}$ & 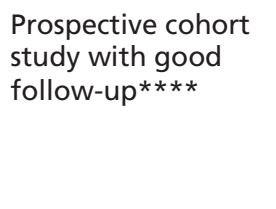 & $\begin{array}{l}\text { Analysis based on clinically } \\
\text { sensible costs or } \\
\text { alternatives; systematic } \\
\text { review(s) of the evidence; } \\
\text { and including multi-way } \\
\text { sensitivity analyses }\end{array}$ \\
\hline $1 c$ & All or none§ & $\begin{array}{l}\text { All or none case- } \\
\text { series }\end{array}$ & $\begin{array}{l}\text { Absolute SpPins and } \\
\text { SnNouts } t \dagger\end{array}$ & $\begin{array}{l}\text { All or none case- } \\
\text { series }\end{array}$ & $\begin{array}{l}\text { Absolute better-value or } \\
\text { worse-value analyses }+\dagger \dagger \dagger\end{array}$ \\
\hline $2 a$ & $\begin{array}{l}\text { SR (with } \\
\text { homogeneity*) of } \\
\text { cohort studies }\end{array}$ & $\begin{array}{l}\text { SR (with } \\
\text { homogeneity*) of } \\
\text { either retrospective } \\
\text { cohort studies or } \\
\text { untreated control } \\
\text { groups in RCTs }\end{array}$ & $\begin{array}{l}\text { SR (with homogeneity*) } \\
\text { of Level > } 2 \text { diagnostic } \\
\text { studies }\end{array}$ & $\begin{array}{l}\text { SR (with } \\
\text { homogeneity*) of } \\
2 \mathrm{~b} \text { and better } \\
\text { studies }\end{array}$ & $\begin{array}{l}\text { SR (with homogeneity*) } \\
\text { of Level > } 2 \text { economic } \\
\text { studies }\end{array}$ \\
\hline $2 b$ & $\begin{array}{l}\text { Individual cohort } \\
\text { study (including low } \\
\text { quality RCT; e.g., } \\
<80 \% \text { follow-up) }\end{array}$ & $\begin{array}{l}\text { Retrospective cohort } \\
\text { study or follow-up of } \\
\text { untreated control } \\
\text { patients in an RCT; } \\
\text { derivation of CDR† or } \\
\text { validated on split- } \\
\text { sample§§§ only }\end{array}$ & $\begin{array}{l}\text { Exploratory** cohort } \\
\text { study with good††† } \\
\text { reference standards; } \\
\text { CDR† after derivation, } \\
\text { or validated only on } \\
\text { split-sample§§§ or } \\
\text { databases }\end{array}$ & $\begin{array}{l}\text { Retrospective } \\
\text { cohort study, or } \\
\text { poor follow-up }\end{array}$ & $\begin{array}{l}\text { Analysis based on clinically } \\
\text { sensible costs or } \\
\text { alternatives; limited } \\
\text { review(s) of the evidence, } \\
\text { or single studies; and } \\
\text { including multi-way } \\
\text { sensitivity analyses }\end{array}$ \\
\hline $2 c$ & $\begin{array}{l}\text { "Outcomes" } \\
\text { research; ecological } \\
\text { studies }\end{array}$ & "Outcomes" research & & Ecological studies & $\begin{array}{l}\text { Audit or outcomes } \\
\text { research }\end{array}$ \\
\hline $3 a$ & $\begin{array}{l}\text { SR (with } \\
\text { homogeneity*) of } \\
\text { case-control studies }\end{array}$ & & $\begin{array}{l}\text { SR (with homogeneity*) } \\
\text { of } 3 \mathrm{~b} \text { and better studies }\end{array}$ & $\begin{array}{l}\text { SR (with } \\
\text { homogeneity*) of } \\
3 \text { b and better } \\
\text { studies }\end{array}$ & $\begin{array}{l}\text { SR (with homogeneity*) of } \\
3 \mathrm{~b} \text { and better studies }\end{array}$ \\
\hline
\end{tabular}


systemic inflammatory response syndrome. ${ }^{22}$ Circulating inflammatory mediators may cause a deviation of patients' core body temperature, heart rate, respiratory rate and white blood cell count. ${ }^{23,24}$ However, inflammatory mediators can be caused by pathological states other than sepsis, such as thermal injury, pancreatitis, acute thyroiditis and traumatic injury. ${ }^{23}$ The clinical syndrome characterized by a noninfective systemic inflammatory response syndrome reaction is similar to those of a septic patient. ${ }^{23,24}$ The only difference is that, in sepsis, micro-organisms have invaded a sterile body tissue. Others have recently revisited the definition of sepsis with a goal to produce a definition that is usable both for the bedside clinician and for research.22

Clinical recognition requires physician knowledge and skill, as septic patients present to the ED with a wide spectrum of illness. Traditionally, 2 or more of the following variables have been used (coupled with evidence/presumption of an infection) to identify patients who are septic: $:^{22,25}$

1. Body temperature less than $36^{\circ} \mathrm{C}$ or greater that $38^{\circ} \mathrm{C}$.

2. A heart rate greater than 90 beats per minute.

3. A respiratory rate greater than 20 breaths per minute, $\mathrm{PACO}_{2}$ less than $30 \mathrm{~mm} \mathrm{Hg}$ or the need for mechanical ventilation.

4. A white count less than 4000 or greater than 12000 , or greater than $10 \%$ immature bands.

Severe sepsis is defined as sepsis in addition to evidence of end organ dysfunction. Virtually any organ system may be affected in severe sepsis. ${ }^{22}$ Organ system dysfunctions

Table 1. Oxford Centre for Evidence-based Medicine Levels of Evidence (May 2001) (Part 2 of 2)

\begin{tabular}{|c|c|c|c|c|c|}
\hline Level & $\begin{array}{l}\text { Therapy/prevention, } \\
\text { etiology/harm }\end{array}$ & Prognosis & Diagnosis & $\begin{array}{l}\text { Differential } \\
\text { diagnosis/symptom } \\
\text { prevalence study }\end{array}$ & $\begin{array}{c}\text { Economic and decision } \\
\text { analyses }\end{array}$ \\
\hline $3 b$ & $\begin{array}{l}\text { Individual case- } \\
\text { control study }\end{array}$ & & $\begin{array}{l}\text { Non-consecutive study; } \\
\text { or without consistently } \\
\text { applied reference } \\
\text { standards }\end{array}$ & $\begin{array}{l}\text { Non-consecutive } \\
\text { cohort study, or very } \\
\text { limited population }\end{array}$ & $\begin{array}{l}\text { Analysis based on } \\
\text { limited alternatives or } \\
\text { costs, poor quality } \\
\text { estimates of data, but } \\
\text { including sensitivity } \\
\text { analyses incorporating } \\
\text { clinically sensible } \\
\text { variations. }\end{array}$ \\
\hline 4 & $\begin{array}{l}\text { Case-series (and } \\
\text { poor quality cohort } \\
\text { and case-control } \\
\text { studies§§) }\end{array}$ & $\begin{array}{l}\text { Case-series (and poor } \\
\text { quality prognostic } \\
\text { cohort studies***) }\end{array}$ & $\begin{array}{l}\text { Case-control study, poor } \\
\text { or non-independent } \\
\text { reference standard }\end{array}$ & $\begin{array}{l}\text { Case-series or } \\
\text { superseded reference } \\
\text { standards }\end{array}$ & $\begin{array}{l}\text { Analysis with no } \\
\text { sensitivity analysis }\end{array}$ \\
\hline 5 & $\begin{array}{l}\text { Expert opinion } \\
\text { without explicit } \\
\text { critical appraisal, or } \\
\text { based on physiology, } \\
\text { bench research or } \\
\text { "first principles" }\end{array}$ & $\begin{array}{l}\text { Expert opinion without } \\
\text { explicit critical } \\
\text { appraisal, or based on } \\
\text { physiology, bench } \\
\text { research or "first } \\
\text { principles" }\end{array}$ & $\begin{array}{l}\text { Expert opinion without } \\
\text { explicit critical appraisal, } \\
\text { or based on physiology, } \\
\text { bench research or "first } \\
\text { principles" }\end{array}$ & $\begin{array}{l}\text { Expert opinion } \\
\text { without explicit } \\
\text { critical appraisal, or } \\
\text { based on physiology, } \\
\text { bench research or } \\
\text { "first principles" }\end{array}$ & $\begin{array}{l}\text { Expert opinion without } \\
\text { explicit critical } \\
\text { appraisal, or based on } \\
\text { economic theory or } \\
\text { "first principles" }\end{array}$ \\
\hline
\end{tabular}

Notes: Users can add a minus-sign "-" to denote the level of that fails to provide a conclusive answer because of

1. EITHER a single result with a wide confidence interval (such that, for example, an ARR in an RCT is not statistically significant but whose confidence intervals fail to exclude clinically important benefit or harm):

2. OR a systematic review with troublesome (and statistically significant) heterogeneity;

3. Such evidence is inconclusive, and therefore can only generate Grade D recommendations.

* By homogeneity we mean a systematic review that is free of worrisome variations (heterogeneity) in the directions and degrees of results between individual studies. Not all systematic reviews with statistically significant heterogeneity need be worrisome, and not all worrisome heterogeneity need be statistically significant. As noted above, studies displaying worrisome heterogeneity should be tagged with a "-" at the end of their designated level.

† Clinical decision rule. (These are algorithms or scoring systems which lead to a prognostic estimation or a diagnostic category.)

\# See note \#2 for advice on how to understand, rate and use trials or other studies with wide confidence intervals.

$\S$ Met when all patients died before the Rx became available, but some now survive on it; or when some patients died before the Rx became available, but none now die on it.

$\S \S$ By poor quality cohort study we mean one that failed to clearly define comparison groups and/or failed to measure exposures and outcomes in the same (preferably

blinded), objective way in both exposed and non-exposed individuals and/or failed to identify or appropriately control known confounders and/or failed to carry out a

sufficiently long and complete follow-up of patients. By poor quality case-control study we mean one that failed to clearly define comparison groups and/or failed to measure

exposures and outcomes in the same (preferably blinded), objective way in both cases and controls and/or failed to identify or appropriately control known confounders.

$\S \S \S$ Split-sample validation is achieved by collecting all the information in a single tranche, then artificially dividing this into "derivation" and "validation" samples.

†+ An "Absolute SpPin" is a diagnostic finding whose Specificity is so high that a Positive result rules-in the diagnosis. An "Absolute SnNout" is a diagnostic finding whose

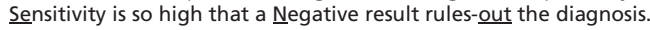

$\neq \ddagger$ Good, better, bad and worse refer to the comparisons between treatments in terms of their clinical risks and benefits.

t+† Good reference standards are independent of the test, and applied blindly or objectively to applied to all patients. Poor reference standards are haphazardly applied, but

still independent of the test. Use of a non-independent reference standard (where the 'test' is included in the 'reference', or where the 'testing' affects the 'reference') implies

a level 4 study.

t††† Better-value treatments are clearly as good but cheaper, or better at the same or reduced cost. Worse-value treatments are as good and more expensive, or worse and the equally or more expensive.

** Validating studies test the quality of a specific diagnostic test, based on prior evidence. An exploratory study collects information and trawls the data (e.g. using a regression analysis) to find which factors are 'significant'.

$* * *$ By poor quality prognostic cohort study we mean one in which sampling was biased in favour of patients who already had the target outcome, or the measurement of outcomes was accomplished in $<80 \%$ of study patients, or outcomes were determined in an unblinded, non-objective way, or there was no correction for confounding factors. $* * * *$ Good follow-up in a differential diagnosis study is $>80 \%$, with adequate time for alternative diagnoses to emerge (e.g., 1-6 months acute, 1-5 years chronic).

Reprinted with permission from the Oxford Centre for Evidence-Based Medicine. ' www.cebm.net/index.aspx?o=1025 
include the central nervous system (agitation, depressed level of consciousness), the cardiovascular system (tachycardia, hypotension, systemic vasodilatation), the gastrointestinal system (elevated liver enzymes), the renal system (elevated creatinine, low urine output) and the hematological system (coagulation dysfunction, thrombocytopenia). Once a patient progresses from sepsis to severe sepsis or septic shock, his or her risk of mortality increases substantially. ${ }^{24,26,27}$

Septic shock is differentiated from severe sepsis by the presence of ongoing cardiovascular instability despite adequate fluid resuscitation. ${ }^{22}$ Systolic blood pressures under $90 \mathrm{~mm} \mathrm{Hg}$ are considered insufficient for optimal cellular homeostasis in septic patients. It is common for septic shock patients to require vasopressor medication infusions for stabilization of the systemic vasodilatation resulting from widespread cytokine release.

The definition of sepsis will continue to evolve as new diagnostic tests are identified to aid in diagnosis. In fact, it is now recognized that patients can be in septic shock without hemodynamic instability ("cryptic shock"). ${ }^{12}$ At the present time, emergency physicians should be familiar with the current definition in order to implement beneficial management options.

\section{The pathophysiology of sepsis}

\section{Question}

What should emergency physicians understand about the pathophysiology of sepsis?

\section{Practice point}

A patient's immune response to microbes results in a myriad of effects that are not limited to the site of infection. Neurohumoral response and vascular cytokine release may result in various organ dysfunctions.

\section{Rationale}

Sepsis is a complex physiological process. Microscopically, once infection is introduced to a host, an initial neuro-

\begin{tabular}{l} 
Table 2. Grades of Recommendation \\
A $\quad \begin{array}{l}\text { consistent level } 1 \text { studies } \\
\text { consistent level } 2 \text { or } 3 \text { studies or extrapolations from } \\
\text { B }\end{array}$ \\
C $\quad \begin{array}{l}\text { level } 1 \text { studies } \\
\text { level } 4 \text { studies or extrapolations from level } 2 \text { or } 3 \\
\text { studies }\end{array}$ \\
D $\quad \begin{array}{l}\text { level } 5 \text { evidence or troublingly inconsistent or } \\
\text { inconclusive studies of any level }\end{array}$ \\
Note: "Extrapolations" are where data is used in a situation that has potentially \\
clinically important differences than the original study situation. \\
$\begin{array}{l}\text { Reprinted with permission from the Oxford Centre for Evidence-Based Medicine.' } \\
\text { www.cebm.net/index.aspx?o=1025 }\end{array}$ \\
\hline
\end{tabular}

humoral response and release of cytokines activates inflammatory mediators. ${ }^{23,24}$ Additional responses include neutrophil adhesion to the endothelium, endothelial disruption and activation of clotting. ${ }^{23-25}$ When combined, these effects contribute to procoagulation and microthromboses at the cellular level. ${ }^{24}$ Excess inflammation and microthromboses lead to cellular hypoxia, anaerobic metabolism and cell death. ${ }^{23}$

On a macroscopic level, sepsis progresses along a spectrum from infectious insult to septic shock and multiorgan dysfunction. ${ }^{25}$ Septic shock is a form of distributive shock, manifested in patients by an increase in cardiac output and vasodilation..$^{24}$ The oxygen demand of end organs exceeds oxygen delivery, and with the cellular switch from aerobic to anaerobic metabolism, lactate is produced. ${ }^{28}$ As oxygen demands remain unmatched, perfusion decreases leading to end organ failure. With each organ system failure, absolute mortality increases by $15 \%-20 \% .^{27}$

\section{Invasive procedures in septic ED patients}

\section{Questions}

1. When is endotracheal intubation indicated in septic patients?

2. When does a septic patient require a central venous line?

3. What location should be used when inserting a central line?

4. Which patients require an arterial line?

\section{Recommendations}

Endotracheal intubation should be instituted when required for airway protection, support of oxygenation or assisted ventilation. (Grade D)

Patients with severe sepsis, sepsis-induced tissue hypoperfusion or hypotension unresponsive to initial fluid resuscitation should have central venous access. (Grade D)

The internal jugular or subclavian veins are the preferred sites for central venous cannulation. (Grade D)

All patients who are receiving vasopressor support should have an arterial line inserted as soon as resources allow. Arterial lines should be strongly considered in patients who are hemodynamically labile or who require frequent blood work and do not have central venous access. (Grade D)

\section{Rationale}

There is little evidence that most invasive procedures influence the outcome of septic patients. Recommendations are based on basic principles and common practice in emergency medicine and critical care medicine. 
Indications for endotracheal intubation are airway protection, or the support of ventilation $\left(\mathrm{CO}_{2}\right.$ clearance) or oxygenation. These situations are common in critically ill septic patients. Positive pressure ventilation can reduce venous return, particularly in patients with an intravascular fluid deficit, and thus decrease blood pressure. Fluid resuscitation should occur prior to and in a simultaneous fashion with intubation to mitigate this effect. Conversely, positive pressure ventilation, in association with sedation, has beneficial effects on hemodynamics by reducing afterload and relieving the effect of work of breathing in the adequately volume-resuscitated patient. ${ }^{29}$

Central venous access in the septic patient may be indicated for the measurement of venous oxygen saturation or central venous pressure or for the infusion of vasoactive medications. A landmark trial of ED sepsis demonstrated that patients who received early goal-directed therapy had a lower mortality rate. ${ }^{12}$ In this study, there were multiple therapeutic interventions given to the treatment group, all with the goal of rapidly improving tissue perfusion. It is unclear which component(s) of the treatment algorithm provided benefit. The "early goal-directed therapy" treatment bundle included the use of central venous oxygen saturation (necessitating the insertion of a central venous catheter) and targeted initial fluid resuscitation to a central venous pressure greater than or equal to 8-12 mm Hg.

Approximately $50 \%$ of septic patients who initially present with severe sepsis will respond to fluids alone. ${ }^{30}$ It is reasonable to perform initial fluid resuscitation targeting clinical end points, such as blood pressure, heart rate and urine output. In situations where there is uncertainty about the adequacy of fluid restoration or concern of fluid overload, central venous monitoring should be started.

Central venous access is usually achieved with placement of subclavian, internal jugular or femoral vein catheters. Venous sampling from these lines is a measure of the mixed venous oxygen saturation and can be used as a surrogate marker of tissue oxygen delivery and extraction. The closer the sample site is to the right ventricle, the more closely it will represent a true mixed venous sample. ${ }^{31}$ Femoral venous samples from septic patients may overestimate the drop in venous saturation, but values from this site remain useful, particularly when trended to evaluate the effectiveness of therapy.

Arterial catheters provide continuous blood-pressure monitoring and facilitate blood sampling. Patients who require vasopressor or inotropic support should have an arterial line inserted as soon as the clinical situation allows, enabling medication titration and monitoring. ${ }^{32}$ Frequent cuff blood-pressure measurement is a reasonable alternative in some clinical situations.

\section{E. Fluid resuscitation in septic ED patients}

\section{Questions}

1. What are the physiologic goals of fluid resuscitation in severe sepsis?

2. What type of fluid should be used to resuscitate septic patients?

3. How much is too much? Can I overresuscitate a patient with septic shock?

\section{Recommendation}

Fluid resuscitation in septic ED patients with tissue hypoperfusion should be initiated immediately upon recognition. (Grade B)

There is currently no conclusive evidence supporting the type of fluid used in resuscitation of the septic patient. Reasonable choices include Ringer's lactate, normal saline or albumin. (Grade D)

An initial bolus of 1-2 L of crystalloid or $500-1000 \mathrm{~mL}$ of colloid should be given over 30-60 minutes and repeated as required to correct tissue perfusion and/or blood pressure abnormalities. (Grade D)

Initial fluid resuscitation should target clinical response, but in patients where there is concern about fluid overload, uncertainty about the adequacy of volume resuscitation or suboptimal response, fluid therapy should be guided by central venous pressure monitoring, targeting a pressure of 8-12 mm Hg. (Grade D)

\section{Rationale}

Septic patients may have a relative intravascular fluid deficit as a result of vasodilation and the loss of intravascular fluid because of an increase in microvascular permeability. In addition, these derangements are often accompanied by fluid losses due to vomiting, diarrhea, diaphoresis, fever, a reduction in fluid intake or bleeding.

The first priority in treating decreased tissue perfusion or hypotension is rapid fluid replacement. Intravascular fluid replacement increases cardiac preload, resulting in higher stroke volume, increased cardiac output and improved organ perfusion.

The volume of fluid administered will depend on patient factors, the progression of the disease state and the type of fluid infused. Rackow found that septic patients often required up to $8 \mathrm{~L}$ of crystalloid or $3 \mathrm{~L}$ of colloid in the first 24 hours. ${ }^{33}$ Patients in the Early Goal-Directed Therapy Trial received an average of $5 \mathrm{~L}$ of fluid in the first 
6 hours. ${ }^{12}$ Fluids should be administered aggressively, targeting clinical signs of improved tissue perfusion, and, if possible, a central venous pressure of $8-12 \mathrm{~mm} \mathrm{Hg}$.

The central venous pressure target of $8-12 \mathrm{~mm} \mathrm{Hg}$ has not been demonstrated to be superior to higher or lower values, but is based on physiologic principles. It is sufficiently high to ensure adequate preload but generally not high enough to promote pulmonary edema formation. Patients undergoing positive pressure ventilation may require higher filling pressures.

Clinicians are often concerned that aggressive intravenous fluid administration will result in pulmonary edema and hypoxia. The majority of septic patients with hypoxia secondary to interstitial fluid accumulation are not truly volume-overloaded; rather, they are suffering from an alveolar capillary leak syndrome. Fluid resuscitation must be tailored to the clinical situation, balancing volume needs and oxygenation to maximize oxygen delivery at the tissue level.

Randomized controlled trials and systematic reviews about the choice of crystalloid or colloid in critically ill patients have not demonstrated a single ideal fluid. ${ }^{3439} \mathrm{~A}$ large trial of 6997 critically ill patients found no mortality or morbidity difference between normal saline and $4 \%$ albumin. ${ }^{34} \mathrm{~A}$ recent comparison of $10 \%$ pentastarch versus Ringer's lactate that focused on severe sepsis patients also found no mortality difference but did report an increase in acute renal failure in the $10 \%$ pentastarch group. ${ }^{40}$ Until further research is completed on the use of starch containing fluids, it would be prudent to avoid their use in septic patients. Overall, the choice should be made based on availability, cost and patient needs. For most patients in the ED, resuscitation with normal saline or lactated Ringer's solutions may be the most appropriate strategy.

\section{F. Vasopressor and inotrope infusions in the ED}

\section{Question}

1. What is the difference between vasopressors and inotropes?

\section{Practice point}

Vasopressor medications increase vascular constriction via peripheral $\alpha$ receptors and therefore increase blood pressure. Inotrope medications increase myocardial contractility and heart rate via $\beta$ receptor stimulation but may not increase blood pressure.

\section{Rationale}

Vasopressors constrict blood vessels, which, in turn, elevates blood pressure. ${ }^{41,42}$ This vasoconstriction is considered beneficial by increasing the perfusion pressure to various tissue beds. Conversely, in some patients vasopressors may increase myocardial afterload and also reduce flow in some vascular beds (e.g., splanchnic). Examples of vasopressors include phenylepherine, norepinephrine and epinephrine.

Inotropes increase cardiac contractility and cardiac output. ${ }^{41,42}$ Commonly used inotropes include dobutamine and milrinone. These drugs will not necessarily increase blood pressure and can lead to a decrease in blood pressure caused by peripheral dilation. Indeed, if the blood pressure is low, it is often necessary to administer an inotrope in combination with a vasopressor to maintain mean arterial pressure. Some medications are a combined vasopressorinotrope, as they contain properties of both (e.g., epinephrine, norepinepherine and dopamine).

\section{Question}

2. When should vasopressors be used?

\section{Recommendations}

After adequate volume resuscitation, vasopressor medications should be used to maintain blood pressure (mean arterial blood pressure $[\mathrm{MAP}]>65 \mathrm{~mm} \mathrm{Hg}$ ) and organ perfusion. (Grade B)

Vasopressor medications may be required to maintain blood pressure prior to adequate volume resuscitation. (Grade D)

\section{Rationale}

Many patients in septic shock who are volume resuscitated (i.e., central venous pressure [CVP] 8-12) remain hypotensive or inadequately perfused. ${ }^{41,42}$ For these patients, vasopressors are recommended to achieve a MAP of greater than $65 \mathrm{~mm} \mathrm{Hg} \cdot{ }^{12,43}$ Other indicators of organ perfusion should be closely monitored, including the level of consciousness, peripheral perfusion and urine output. In most individuals, a urine output of $0.5 \mathrm{~mL} / \mathrm{kg} / \mathrm{h}$ is acceptable.

In the ED, patients in septic shock are often initially hypovolemic and hypotensive. Vasopressors may be used concurrently with volume resuscitation to maintain blood pressure until adequate volume status can be established. ${ }^{44-46}$ Once the patient is volume resuscitated, vasopressor infusion should be reduced if physiologic goals are achieved.

\section{Question}

3. Which vasopressor should be used?

\section{Recommendation}

Various vasopressors, including norepinepherine and dopamine, may be used in septic shock. (Grade C) 


\section{Rationale}

Insufficient data is available to definitively conclude which optimal vasopressor should be used in septic patients. However, there is sufficient data to recommend the use of norepinepherine (levophed) and dopamine as first-line agents. ${ }^{45,47-49}$

Both norepinepherine and dopamine increase MAP in volume-replete patients in septic shock. ${ }^{32,44,45,47,48,50}$ In addition, there is evidence that norepinepherine may increase MAP in patients who are refractory to the administration of intravenous fluids and dopamine. ${ }^{49,51-57}$ However, dopamine has been in widespread use in the ED for decades and is conveniently supplied in a premixed solution.

Recommended dopamine doses range from 1 to 25 $\mu \mathrm{g} / \mathrm{kg} / \mathrm{min} .{ }^{45}$ Low-dose dopamine does not protect critically ill patients from renal dysfunction and infusions at that rate for that purpose should no longer be used. ${ }^{58,59}$ Low-dose dopamine $(<5 \mu \mathrm{g} / \mathrm{kg} / \mathrm{min})$ may increase urine output but does not reduce multiorgan dysfunction or the need for renal replacement therapy. ${ }^{58,60}$

Norepinepherine should be titrated based on patient response, including blood pressure and urinary output. ${ }^{32,45}$ Norepinepherine does not worsen renal dysfunction in septic patients. ${ }^{49,55,57}$

Other vasopressors, such as epinephrine and vasopressin, may also be used in septic patients, although current practice in Canadian EDs is limited. Vasopressin is a potent vasoconstrictor that acts as an agonist at the $\mathrm{V} 1$ receptor to constrict vascular smooth muscle. It may be used as an adjunct to decrease the dose of other vasopressors in septic shock. ${ }^{61-63}$ Epinephrine increases mean arterial pressure, but concerns exist as it may impair splanchnic circulation and raise lactate levels in septic patients. ${ }^{47}$

\section{Question}

4. How should vasopressors be administered in the ED (central v. peripheral)?

\section{Practice point}

Vasopressors should be administered through a central venous line in the ED.

\section{Rationale}

It may be necessary to deliver vasopressors peripherally until a central line can be established in the ED. While vasopressors can be delivered peripherally in a temporary fashion, the risks of this practice include vein sclerosis, extravasation and inadequate or uncertain delivery ${ }^{64}{ }^{67}$ Central access should be established in all septic shock patients as soon as possible, given the competing clinical demands of the department. Central-line insertion also allows for rapid fluid infusion and central venous oxygen saturation monitoring.

\section{Question}

5. When should inotropes be used?

\section{Recommendation}

Inotropes should be used to maintain central venous oxygen saturation over $70 \%$ (Grade D) and adequate cardiac output (Grade D) in volume-replete septic patients who have an adequate blood pressure.

\section{Rationale}

A pivotal study of early goal-directed therapy in the ED demonstrated the utility of optimal saturation of the venous blood returning to the right ventricle after being deoxygenated in peripheral tissues. ${ }^{12}$ Inotropes should be titrated to maintain central venous oxygen saturation greater than $70 \%$ (a measure of adequate resuscitation) as part of early goal-directed therapy in septic shock. ${ }^{12}$ Specifically, these patients should have a CVP of $8-12 \mathrm{~mm} \mathrm{Hg}$, a mean arterial pressure greater than $65 \mathrm{~mm} \mathrm{Hg}$, adequate urine output and a hematocrit (Hct) over 30\%, prior to initiation of inotropes to improve oxygen delivery. ${ }^{12,44,45}$ This therapy usually requires a subclavian or an internal jugular central line for appropriate monitoring and titration. Ideally, inotropes should not be titrated to blood pressure alone, but should include ongoing assessment of the patient's overall progress.

\section{Question}

6. Which inotrope should be used?

\section{Recommendation}

Dobutamine is considered first line in septic shock patients who require inotropic support. (Grade D)

\section{Rationale}

Inotropes have been studied less extensively than vasopressors in septic shock. Dobutamine, in doses of $2-28 \mu \mathrm{g} / \mathrm{kg} / \mathrm{min}$, effectively raises cardiac output in this population. ${ }^{45,68}$ However, caution is warranted, as tachycardia and hypotension are common in patients receiving dobutamine. The avoidance of further hypotension is important and, therefore, patients often require additional vasopressor infusions when dobutamine is required. Milrinone infusion may be considered if tachycardia limits the use of dobutamine.

\section{G. Microbial cultures in the ED}

\section{Question}

1. What is the importance of cultures in septic ED patients? 


\section{Recommendation}

The establishment of a microbiological diagnosis and confirmation of effective antimicrobial therapy requires cultures of all potentially infected sites. (Grade D)

\section{Rationale}

Data on the benefit of body fluid cultures in septic ED patients is incomplete. Unfortunately, cultures are often negative, and the yield is influenced by the source of infection and type of culture. For example, one series states that no more than $50 \%$ of patients with severe sepsis will have positive blood cultures. ${ }^{3}$ However, as a "standard-of-care," patients with possible severe sepsis should have all potential sources of infection cultured. ${ }^{69}$ Cultures maximize information to aid in the establishment of a definitive microbiological diagnosis, utilizing appropriate antibiotics and providing data about local pathogens and antibiotic resistance.

\section{Question}

2. When should cultures be obtained in septic emergency patients?

\section{Recommendation}

Cultures should be obtained as soon as a patient is identified as potentially septic. Ideally, this should be done prior to antimicrobial administration, but should not delay treatment. (Grade D)

\section{Rationale}

Insufficient data exists on the timing of culture acquisition to definitively answer this question. Regardless, it is generally accepted that cultures should be obtained prior to the initiation of antibiotic therapy. ${ }^{44}$ This offers the best yield, and assists in the re-evaluation of antimicrobials when cultures results are available 24-72 hours later. However, given mounting evidence that delaying antibiotic therapy is harmful (see section I. Antimicrobial administration in early sepsis), cultures should be drawn as soon as possible and should not delay treatment.

\section{Question}

3. How and where should cultures be obtained?

\section{Recommendation}

Cultures should be obtained from all potential sources of infection. (Grade D)

\section{Rationale}

Cultures drawn in septic ED patients should be dictated by the suspected source of infection. Usual practice is to obtain blood cultures from all potentially infected sites. This typically means peripheral blood, urine and sputum cultures. Other sources, such as cerebrospinal fluid, cutaneous wounds and indwelling vascular access devices should also be cultured based on clinical suspicion. The use of standard protocol for obtaining blood cultures can result in better yield and less contamination..$^{70}$ To maximize yield, a minimum of $20 \mathrm{~mL}$ per blood culture is recommended ( 2 bottles of $10 \mathrm{~mL}$ each). ${ }^{71,72}$

\section{H. Bedside prognostication of patients with sepsis}

\section{Question}

Are there bedside predictors of outcome in septic patients?

\section{Recommendation}

The elevation of serum lactate in patients with sepsis is associated with an increase in mortality. Organ dysfunction also indicates an increased risk of death. (Grade B)

\section{Rationale}

Lactate is generated during anaerobic cellular metabolism and is a hallmark of severe sepsis or septic shock. Lactate has been studied in a variety of clinical conditions in critical care medicine and has been demonstrated to predict mortality with varied accuracy. ${ }^{28,73-77}$ Original work in the 1960s in patients with shock and elevated lactates $(>4 \mathrm{mmol} / \mathrm{L})$ demonstrated a mortality rate greater than $80 \% .{ }^{73}$ Bernardin also found that a lactate of $>3.5 \mathrm{mmol} / \mathrm{L}$ at 24 hours after admission was associated with elevated mortality (approximately 30\%). ${ }^{74}$ Another trial of 1228 patients with infection-related diagnoses found that a lactate of greater than $4 \mathrm{mmol} / \mathrm{L}$ was associated with a mortality of $22 \%$ within 3 days, versus $2 \%$ for patients with a lactate of less than $4 \mathrm{mmol} / \mathrm{L} .{ }^{75}$ Conversely, patients in whom serum lactate decreases after ED therapy have an associated reduction in mortality. ${ }^{28}$ Although lactate may be generated by various mechanisms, the elevation of serum lactate in a patient with septic shock indicates that emergent resuscitation is required. Early measurement of serum lactate may aid in the identification of patients where the severity of the infection may otherwise be underappreciated.

Organ dysfunction in patients with severe sepsis also predicts mortality ${ }^{78}$ An ED-based observational cohort study of 3102 patients with suspected infection demonstrated a 4-fold increase of in-hospital mortality in patients with severe sepsis (failure of 1 or more organs) versus patients without organ dysfunction. An increase in mortality risk was demonstrated as the number of dysfunctional organs increased. In patients with septic shock 
on ED presentation and organ dysfunction, the risk of death was 13 times higher than in septic patients without organ dysfunction. ${ }^{78}$

\section{Antimicrobial administration in early sepsis}

\section{Question}

1. When should antibiotics be administered?

\section{Recommendation}

Patients presenting with severe sepsis/septic shock should receive broad spectrum antibiotics as soon as possible, ideally within 60 minutes of the recognition of severe sepsis. (Grade C)

\section{Rationale}

Rapid administration of antibiotics to patients with severe sepsis/septic shock should be considered of paramount importance. Animal models suggest that the administration of antibiotics within 12 hours resulted in a mortality rate of $20 \%$ versus over $85 \%$ if delayed for more than 15 hours. $^{79}$ Prospective human trials in severe sepsis/septic shock are lacking, but studies in meningitis suggest delaying antibiotics over one hour is associated with increased mortality. ${ }^{80}$ Patients with community-acquired pneumonia also had similar reductions in mortality. Houck and colleagues ${ }^{81}$ found that those patients who received antibiotics within 4 hours of arrival had lower mortality (11.6\% v. $12.7 \%$ ), and decreased length of hospital stay. Kumar and coauthors $^{82}$ retrospectively studied over 2000 patients with septic shock. Patients who received antibiotics within the first hour had a mortality of $20 \%$, and delayed antimicrobial administration was associated with increased mortality. The study concluded that timing of antibiotic administration was the most significant determinant of outcome and that for every hour delay following onset of hypotension mortality increased by $8 \% .{ }^{82}$ In addition, only $50 \%$ of patients in this study received antibiotics within the first 6 hours of diagnosis of septic shock in the ED. Measures to ensure that antimicrobials are administered immediately by a member of the health care team are recommended.

\section{Question}

2. What antibiotics should be administered?

\section{Recommendation}

The administration of appropriate antimicrobials should provide appropriate coverage against all likely pathogens and should be based on patient characteristics and local epidemiology and resistance patterns. (Grade B)

\section{Rationale}

It is well established that appropriate initial antimicrobial therapy in sepsis reduces morbidity and mortality. Multiple studies in patients with gram negative bacteremia have demonstrated an approximate $50 \%$ reduction in mortality with appropriate antimicrobial therapy. ${ }^{18-21}$ Specific antimicrobial recommendations are beyond the scope of this document but several published recommendations exist. ${ }^{83,84}$ Emphasis should be on initial broadspectrum coverage and should reflect the likely source and the local resistance patterns. Either monotherapy or dual therapy in uncomplicated cases is acceptable based on available data.

\section{Question}

3. Are there special circumstances that modify antimicrobial recommendations in ED patients?

\section{Recommendation}

In patients with neutropenia or who are immunocompromised, the possibility of infection with Pseudomonas sp. must be considered. Coverage with 2 antimicrobial agents effective against this organism should be considered. (Grade D)

\section{Rationale}

Immunocompromised patients are at high risk of serious infection with Pseudomonas sp. Controversy remains as to the benefit of prolonged dual therapy versus monotherapy, but it is generally agreed that initial dual therapy coverage is appropriate for serious infection..$^{81,83,84}$ The Infectious Diseases Society of America recently published guidelines that address this issue. ${ }^{85}$

Other special circumstances include nursing home patients, patients recently discharged from a health care facility and those recently $(<3 \mathrm{mo})$ or currently receiving antimicrobial medications. EM physicians should consider these factors when deciding on appropriate antimicrobial therapy.

\section{J. Source control in sepsis}

\section{Question}

Is source control important in patients with severe sepsis?

\section{Recommendation}

Optimal treatment includes consideration of all potential sources of infection and their subsequent control or elimination. As with antimicrobials, source control should be a priority in ED management. (Grade D) 


\section{Rationale}

Source control should be a primary focus in the initial management of septic patients in the ED..$^{44,86}$ Unfortunately, the identification and removal of a focus of infection may often be overlooked. Examples include removing potentially infected venous catheters, draining abscesses and debriding necrotic tissue (such as in necrotizing fasciitis). Recommendations are largely based upon expert opinion rather than randomized trials ${ }^{86}$ Several case series and case reports have suggested the superiority of early source control versus late or no control at all. For example, one small case series reporting on children with necrotizing fasciitis found that delayed debridement of infected tissue was associated with high mortality rates ${ }^{87}$ As such, source control should occur as soon as possible. ${ }^{44,86}$

\section{$K$. The use of activated protein $C(A P C)$ in the $E D$}

\section{Question}

What is the role of APC in the ED?

\section{Recommendation}

APC infusions may be considered in adult patients with severe sepsis (Acute Physiology and Chronic Health Evaluation [APACHE] II $\geq 25$, or 2 or more organ dysfunctions) within 24 hours of diagnosis. (Grade B)

Little data is available on the use of APC in the ED.

\section{Rationale}

APC is an anticoagulant that combats the hypercoagulable state associated with sepsis by various mechanisms. ${ }^{88,89}$ Administration requires a weight-based, 96-hour infusion protocol that is combined with other standard supportive care measures. Based on a prospective randomized controlled trial of 1690 patients with severe sepsis that demonstrated a $6.1 \%$ absolute mortality reduction, APC is used in the management of severely septic patients. ${ }^{15}$

In the United States, APC received an indication from the Food and Drug Administration for the treatment of severe sepsis in patients with an APACHE II score of 25 or greater. Most Canadian health jurisdictions have adopted similar indications, although some centres instead use greater than 2 organ system dysfunction as an indication. Surgical patients and those with active bleeding or a significant risk of blood loss are not suitable candidates for APC, as the risk of hemorrhage is increased. In addition, APC is not indicated for patients with sepsis who have a low risk of death (APACHE II score $<25$ or $\leq 1$ organ dysfunction) or for children.$^{90}$

Data on the use of APC in an ED setting is incomplete.
To date, there exists no placebo-controlled, double-blind, randomized controlled trial specifically examining the issue of timing of APC administration. Post hoc analysis of available data indicates the potential for improved outcome with earlier administration in select patients. ${ }^{91}$

Since the use of APC is based on septic patients having an APACHE II score of 25, and with limited data on its use in the ED, APC should not be routinely administered in the $\mathrm{ED}$, unless under the direction of an intensivist or infectious disease specialist.

\section{Corticosteroid use in septic ED patients}

\section{Question}

1. When should corticosteroids be used in septic ED patients?

\section{Recommendation}

Hemodynamically unstable patients who do not respond to volume resuscitation and vasopressor infusion may be considered for low-dose corticosteroid replacement in the ED. (Grade D)

\section{Rationale}

The use of low-dose corticosteroids in severe sepsis is supported by recent trials and meta-analyses, although significant controversy remains. ${ }^{16,92-95}$ Annane and coauthors ${ }^{16}$ randomized vasopressor-dependent septic patients to receive either placebo or hydrocortisone $50 \mathrm{mg}$ intravenously (IV) every 6 hours and fludrocortisones $50 \mu \mathrm{g}$ orally once daily. Patients were also administered a $0.25-\mathrm{mg}$ adrenocorticotropic hormone (ACTH) stimulation test in both groups to determine the adrenal response to direct stimulation. Among nonresponders to ACTH, 28-day mortality was significantly reduced in the steroid group at $53 \%$ versus $63 \%$ for the control group $(p=0.04) .{ }^{16}$ There was no statistical difference in corticosteroid-related complications, such as additional infections or gastrointestinal bleeding. ${ }^{16}$

Other authors have also investigated the utility of corticosteroids in septic patients. ${ }^{92-95}$ Two meta-analyses concluded a benefit for the administration of low-dose corticosteroids (200-300 mg/d of hydrocortisone equivalents) in ICU patients with septic shock. ${ }^{96,97}$ Annane and colleagues $^{98}$ reviewed trials involving low-dose corticosteroid for at least 5 days found a significant decrease in mortality (relative risk [RR] 0.80, 95\% confidence interval $[\mathrm{CI}] 0.67-0.95, p=0.01)$. In addition, a meta-analysis performed by Minneci and colleagues ${ }^{96}$ determined that low-dose glucocorticoids provided a beneficial effect on 
survival (RR 1.23, 95\% CI 1.01-1.50, $p=0.036$ ) and shock reversal (RR 1.71, 95\% CI 1.29-2.26, $p<0.001$ ).

However, the corticosteroid therapy of septic shock (CORTICUS) trial, which randomized 499 severe septic patients to receive corticosteroids or placebo, failed to confirm a benefit of steroids in sepsis. ${ }^{99}$ In this study, mortality was not affected by the use of corticosteroids despite more rapid resolution of hemodynamic instability in patients receiving corticosteroids. In addition, there was an increased incidence of infectious complications in patients who received corticosteroids. Unfortunately, this study suffered from a lack of power because of its premature termination secondary to poor recruitment and the loss of funding. In addition, etomidate use in patients requiring intubation was identified as a possible confounder, as it has been associated with adrenal insufficiency.

Based on the available evidence, corticosteroids may be considered in patients with severe sepsis and hemodynamic instability. The utility of corticosteroids remains unproven.

\section{Question}

2. How should steroids be used in patients with septic shock?

\section{Recommendation}

Doses of 200-300 mg per day of hydrocortisone may be considered in patients requiring vasopressor support. (Grade D)

\section{Rationale}

Low-dose corticosteroid replacement may be considered in septic shock patients. With the exception of 1 trial, ${ }^{92}$ the entry criteria for studies involving low-dose corticosteroids required the use of vasopressor support. ${ }^{1693-95}$ Annane and colleagues ${ }^{16}$ required a systolic blood pressure less than $90 \mathrm{~mm} \mathrm{Hg}$ for at least 1 hour despite adequate fluid replacement and the use of dopamine at a dose greater than $5 \mu \mathrm{g} / \mathrm{kg} / \mathrm{min}$ or current treatment with norepinephrine or epinephrine.

Hydrocortisone may be used for glucocorticoid replacement, in doses of 200-300 mg/d in divided (every 6-8 h) doses. The use of additional mineralocorticoid replacement is controversial.

The considerable heterogeneity in the use of the ACTH stimulation test ${ }^{100-104}$ led a recent review to conclude that the ACTH test is optional. ${ }^{105}$ In addition, some centres may take several days to return ACTH stimulation results, which may reduce the relevance of this test. The administration of corticosteroids should not be delayed pending the results of the ACTH test. Rather, the ACTH test should be performed and blood sent to the receiving laboratory, followed by the immediate administration of corticosteroids in the ED. The receiving ICU can then re-evaluate the continuation of corticosteroids once the results of the ACTH test are available.

Alternatively, ED physicians may administer dexamethasone (4-6 mg IV), which will not interfere with future ACTH stimulation testing and serum cortisol determination and will provide the required glucocorticoid effect.

\section{Blood transfusions in septic ED patients}

\section{Question}

Should packed red blood cells (PRBCs) be administered to ED patients with early septic shock?

\section{Recommendation}

During acute sepsis resuscitation, patients with normal CVPs (8-12 mm Hg) and low central venous oxygen saturations $(<70 \%)$ should receive blood transfusions to target a Hct of $>30 \%$. (Grade B)

\section{Rationale}

The optimum hemoglobin (Hgb) level in severe sepsis has not been clearly established. The transfusion requirements in critical care (TRICC) trial studied euvolemic critically ill patients and randomized them to transfusions when a patient's $\mathrm{Hgb}$ was less than $70 \mathrm{~g} / \mathrm{L}$ versus an $\mathrm{Hgb}$ of less than $100 \mathrm{~g} / \mathrm{L}{ }^{106}$ The primary outcome of 30-day mortality was not significantly different between the 2 groups. Subgroup analysis revealed lower mortality rates in patients with a transfusion threshold of $\mathrm{Hgb}$ of $70 \mathrm{~g} / \mathrm{L}$ in patients who were less ill and younger, and similar mortality rates in patients with coronary artery disease (AMI or angina). However, in a subgroup analysis, there was a trend toward increased death in patients with severe ischemic heart disease. As such, a recommended practice in the euvolemic critically ill patient is to transfuse when the Hgb is less than $70 \mathrm{~g} / \mathrm{L}$, or when less than $90-100 \mathrm{~g} / \mathrm{L}$ if there is a history of coronary artery disease. ${ }^{106}$

However, septic shock patients are often hypovolemic and unstable. As such, they differ from the TRICC trial population. In contrast, in the Early Goal Directed Therapy trial, Rivers and colleagues ${ }^{12}$ transfused to achieve a Hct of $30 \%$ as part of a sepsis resuscitation algorithm. In this algorithm, transfusion of PRBCs was provided to patients with adequate CVPs and mean arterial pressures, but with low central venous oxygen saturations. Substantial reduction in patient mortality was demonstrated with 
the use of this algorithm. Unfortunately, the impact of PRBC administration was not independently assessed. ${ }^{12}$ EM physicians should ensure that patients have an adequate amount of oxygen-carrying red blood cells, and if a patient's central venous oxygen saturation is less than $70 \%$, PRBCs should be administered to achieve a Hct of greater than $30 \%$.

\section{N. Mechanical ventilation in septic ED patients requiring intubation}

\section{Question}

1. How should patients with sepsis and respiratory failure be ventilated?

\section{Recommendation}

Assist control ventilation (ACV) may be used as the initial ventilation mode with an initial $\mathrm{FiO}_{2}$ of 1.0 , positive end expiratory pressure (PEEP) of $5-15 \mathrm{~cm} \mathrm{H}_{2} 0$; a rate of 15-25 breaths per minute (bpm). (Grade D)

The goal is to achieve arterial oxygen saturation greater than $90 \%$; a $\mathrm{pH}$ greater than 7.25 ; and a $\mathrm{FiO}_{2} 0.6$ or less. (Grade B)

\section{Rationale}

The goal of mechanical ventilation is to maintain tissue oxygenation and avoid severe acidosis, while minimizing additional lung damage and the progression to multisystem organ failure. ${ }^{107,108}$ During acute resuscitation, tissue oxygen delivery and the avoidance of severe acidosis $(\mathrm{pH}<7.25)$ are initial physiological goals of ventilation, despite transient high airway pressures and tidal volumes. However, repetitive alveoli collapse and opening is thought to propagate lung injury, and therefore strategies should be employed to minimize barotrauma and volutrauma after patient stabilization. ${ }^{44,107-111}$

Although few trials have demonstrated the optimal mode of ventilation, ACV is commonly utilized after emergent airway control as patients are often given sedatives and neuromuscular blockers in the ED. Ventilator settings, such as $\mathrm{Fi}_{2}$, respiratory rate and PEEP, must be individualized. As such, many patients may be started on $\mathrm{ACV}$, at a $\mathrm{FiO}_{2}$ of 1.0, PEEP of 5-15 $\mathrm{cm} \mathrm{H}_{2} 0$; a rate of $15-25$ beats/min initially. Overall, the primary goal is to achieve arterial oxygen saturation greater than $90 \%$ and $\mathrm{pH}$ less than 7.25. Secondary goals include $\mathrm{FiO}_{2} 0.6$ or less, peak airway pressures of less than $40 \mathrm{~cm} \mathrm{H}_{2} 0$ and plateau pressures of less than $30 \mathrm{~cm} \mathrm{H}_{2} \mathrm{O}$.

Other modes of ventilation, such as pressure support ventilation, may be utilized in more stable patients.

\section{Question}

2. What ventilator parameters are important to minimize additional lung injury?

\section{Recommendation}

Patients should receive tidal volumes of $6 \mathrm{~mL} / \mathrm{kg}$ of ideal body weight and have end-inspiratory plateau pressures of less than $30 \mathrm{~cm} \mathrm{H}_{2} \mathrm{O}$ to minimize additional lung dysfunction. (Grade B)

\section{Rationale}

Acute lung injury can result from direct lung injury (e.g., pneumonia, aspiration) or via a systemic response to nonpulmonary disease (e.g., severe nonpulmonary sepsis). ${ }^{110,111}$ Optimal mechanical ventilation may be "protective," as it minimizes additional ventilator-induced lung injury. ${ }^{107,108,112-114}$

Further lung damage can result from regional overdistention related to high ventilatory volumes (volutrauma), high pressures (barotrauma) and cyclic opening and closing of alveoli with resultant shear injury. ${ }^{112,13,115-119} \mathrm{~A}$ multicentre trial that gradually decreased tidal volumes to $6 \mathrm{~mL} / \mathrm{kg}$ of ideal body weight (as opposed to $10-12 \mathrm{~mL} / \mathrm{kg}$ ) and aimed for end-inspiratory plateau pressures of less than $30 \mathrm{~cm} \mathrm{H}_{2} \mathrm{O}$, showed a $22 \%$ decrease in mortality. ${ }^{109}$ Decreasing ventilatory volume means permitting moderate hypercapnea. However, "permissive hypercapnea" is safe, providing severe acidosis is avoided, and as long as the patient can hemodynamically tolerate the sedatives required to overcome their respiratory drive. ${ }^{112,115}$ In contrast to initiating this approach immediately, reducing tidal volume over several hours minimizes the hemodynamic consequences of acute hypercapnea (acidosis, vasodilation, increased right ventricular pressure vasodilation). ${ }^{44}$ Sodium bicarbonate, by bolus or infusion, may be required if acidosis becomes pronounced. ${ }^{107,108,112,115}$

\section{O. Serum glucose control in the $E D$}

\section{Question}

Should serum glucose be manipulated in septic ED patients?

\section{Recommendation}

Both hyperglycemia and hypoglycemia should be avoided in acute sepsis. Blood glucose should be maintained within normal range (4-8 mmol/L) in septic ED patients. (Grade D)

\section{Rationale}

A single-centre European study of 1600 surgical ICU patients 
compared the use of an insulin infusion to maintain blood glucose between 4.4-6.1 mmol/L ("tight glycemic control") with 10-12 mmol/L ("conventional glucose control"). Tight glycemic control was associated with improved mortality and morbidity. ${ }^{17}$ However, questions have remained about its generalizability of tight glucose control for patients with early sepsis, as this study was in postoperative surgical patient. Further evaluation of medical ICU patients also found a morbidity benefit but no overall mortality benefit with tight glycemic control. Unfortunately, this study demonstrated a substantial incidence of hypoglycemia associated with tight glucose control. ${ }^{120}$

As such, it is prudent to avoid both hyperglycemia and hypoglycemia in the acute treatment of sepsis. ${ }^{121}$ Studies have not focused on ED patients, and several multicentre ICU trials are still underway to confirm the benefit of tight glucose control. However, without invasive and frequent monitoring, attempts at such tight control in the ED may put the patient at risk for dangerous hypoglycemia.

According to the available data, a euglycemic range of 4-8 $\mathrm{mmol} / \mathrm{L}$ appears reasonable in ED patient. ${ }^{17,40,120}$

In patients who are critically ill, reduced blood flow to skin and muscles may limit insulin uptake with subcutaneous or intramuscular routes. IV insulin should be used for glucose control in the ED.

External reviewers: Richard I. Hall, MD, Professor, Departments of Anesthesia, Medicine \& Pharmacology, Associate Professor, Surgery, Dalhousie University, Queen Elizabeth II Health Sciences Centre; Lauralyn MacIntyre, MD, MSc, Assistant Professor, Department of Medicine (Division of Critical Care), Associate Scientist, Ottawa Health Research Institute, Centre for Transfusion and Critical Care Research, Ottawa Hospital; Jason A. Lord, MD, MSc, Intensivist, Emergency Physician, Resident Education Coordinator - Critical Care Medicine, Peter Lougheed Centre, Calgary Health Region.

Other support provided by: Marlene Murphy, Administration Assistant, Department of Medicine, Division of Critical Care Medicine, Queen Elizabeth II Health Sciences Centre, Capital District Health Authority, Dalhousie University; David Urquart, Database Consultant, Department of Emergency Medicine, Dalhousie University

Competing interests: None declared.

\section{References}

1. Phillips B, Ball C, Sackett D, et al. Oxford Centre for Evidencebased Medicine levels of evidence (May 2001). Available: www.cebm.net/levels_of_evidence.asp (accessed March 2008).

2. Strehlow MC, Emond SD, Shapiro NI, et al. National study of emergency department visits for sepsis, 1992 to 2001. Ann Emerg Med 2006;48:326-31, 331.e1-3.

3. Martin GS, Mannino DM, Eaton S, et al. The epidemiology of sepsis in the United States from 1979 through 2000. N Engl J Med 2003 17;348:1546-54.

4. Angus DC, Linde-Zwirble WT, Lidicker J, et al. Epidemiology of severe sepsis in the United States: analysis of incidence, outcome, and associated costs of care. Crit Care Med 2001;29:1303-10.

5. Lambe S, Washington DL, Fink A, et al. Trends in the use and capacity of california's emergency departments, 1990-1999. Ann Emerg Med 2002;39:389-96.

6. Meggs WJ, Czaplijski T, Benson N. Trends in emergency department utilization, 1988-1997. Acad Emerg Med 1999;6:1030-5.

7. Parkhe M, Myles PS, Leach DS, et al. Outcome of emergency department patients with delayed admission to an intensive care unit. Emerg Med (Fremantle) 2002;14:50-7.

8. Nelson M, Waldrop RD, Jones J, et al. Critical care provided in an urban emergency department. Am J Emerg Med 1998;16:56-9.

9. Varon J, Fromm RE Jr, Levine RL. Emergency department procedures and length of stay for critically ill medical patients. Ann Emerg Med 1994;23:546-9.

10. Svenson J, Besinger B, Stapczynski JS. Critical care of medical and surgical patients in the ED: Length of stay and initiation of intensive care procedures. Am J Emerg Med 1997;15:654-7.

11. Sampalis JS, Denis R, Lavoie A, et al. Trauma care regionalization: a process-outcome evaluation. J Trauma 1999;46:565,79; discussion 579-81.

12. Rivers E, Nguyen B, Havstad S, et al. Early goal-directed therapy in the treatment of severe sepsis and septic shock. N Engl J Med 2001;345:1368-77.

13. Cannon CP, Gibson CM, Lambrew CT, et al. Relationship of symptom-onset-to-balloon time and door-to-balloon time with mortality in patients undergoing angioplasty for acute myocardial infarction. JAMA 2000;283:2941-7.

14. Tissue plasminogen activator for acute ischemic stroke. The National Institute of Neurological Disorders and Stroke rt-PA Stroke Study Group. N Engl J Med 1995;333:1581-7.

15. Bernard GR, Vincent JL, Laterre PF, et al. Efficacy and safety of recombinant human activated protein $\mathrm{C}$ for severe sepsis. N Engl J Med 2001;344:699-709.

16. Annane D, Sebille V, Charpentier C, et al. Effect of treatment with low doses of hydrocortisone and fludrocortisone on mortality in patients with septic shock. JAMA 2002;288:862-71.

17. van den $B G$, Wouters $P$, Weekers $F$, et al. Intensive insulin therapy in the critically ill patients. N Engl J Med 2001;345: 1359-67.

18. Bochud PY, Bonten M, Marchetti O, et al. Antimicrobial therapy for patients with severe sepsis and septic shock: an evidencebased review. Crit Care Med 2004;32:S495-512.

19. Garnacho-Montero J, Garcia-Garmendia JL, Barrero-Almodovar A, et al. Impact of adequate empirical antibiotic therapy on the outcome of patients admitted to the intensive care unit with sepsis. Crit Care Med 2003;31:2742-51.

20. Leibovici L, Shraga I, Drucker M, et al. The benefit of appropriate empirical antibiotic treatment in patients with bloodstream infection. J Intern Med 1998;244:379-86.

21. Leone M, Bourgoin A, Cambon S, et al. Empirical antimicrobial therapy of septic shock patients: adequacy and impact on the outcome. Crit Care Med 2003;31:462-7. 
22 Levy MM, Fink MP, Marshall JC, et al. 2001 SCCM/ESICM/ ACCP/ATS/SIS International Sepsis Definitions Conference. Crit Care Med 2003;31:1250-6.

23. Hotchkiss RS, Karl IE. The pathophysiology and treatment of sepsis. N Engl J Med 2003;348:138-50.

24. Rivers EP, McIntyre L, Morro DC, et al. Early and innovative interventions for severe sepsis and septic shock: taking advantage of a window of opportunity. CMAJ 2005;173:1054-65.

25. Bone RC, Balk RA, Cerra FB, et al. Definitions for sepsis and organ failure and guidelines for the use of innovative therapies in sepsis. The ACCP/SCCM Consensus Conference Committee. American College of Chest Physicians/Society of Critical Care Medicine. Chest 1992;101:1644-55.

26. Rivers E. The outcome of patients presenting to the emergency department with severe sepsis or septic shock. Crit Care 2006; 10:154.

27. Hebert PC, Drummond AJ, Singer J, et al. A simple multiple system organ failure scoring system predicts mortality of patients who have sepsis syndrome. Chest 1993;104:230-5.

28. Nguyen HB, Rivers EP, Knoblich BP, et al. Early lactate clearance is associated with improved outcome in severe sepsis and septic shock. Crit Care Med 2004;32:1637-42.

29. Pinsky MR. Cardiovascular effects of ventilatory support and withdrawal. Anesth Analg 1994;79:567-76.

30. Sugerman HJ, Diaco JF, Pollock TW, et al. Physiologic management of septicemic shock in man. Surg Forum 1971;22:3-5.

31. Turnaoglu S, Tugrul M, Camci E, et al. Clinical applicability of the substitution of mixed venous oxygen saturation with central venous oxygen saturation. J Cardiothorac Vasc Anesth 2001; 15:574-9.

32. Practice parameters for hemodynamic support of sepsis in adult patients in sepsis. Task Force of the American College of Critical Care Medicine, Society of Critical Care Medicine. Crit Care Med 1999;27:639-60.

33. Rackow EC, Falk JL, Fein IA, et al. Fluid resuscitation in circulatory shock: a comparison of the cardiorespiratory effects of albumin, hetastarch, and saline solutions in patients with hypovolemic and septic shock. Crit Care Med 1983;11:839-50.

34. Finfer S, Norton R, Bellomo R, et al. The SAFE study: saline vs. albumin for fluid resuscitation in the critically ill. Vox Sang 2004;07(Suppl 2):123-31.

35. Bunn F, Alderson P, Hawkins V. Colloid solutions for fluid resuscitation. Cochrane Database Syst Rev 2003; (1):CD001319.

36. Roberts I, Alderson P, Bunn F, et al. Colloids versus crystalloids for fluid resuscitation in critically ill patients. Cochrane Database Syst Rev. 2004;(4):CD000567

37. Alderson P, Bunn F, Lefebvre C, et al. Human albumin solution for resuscitation and volume expansion in critically ill patients. Cochrane Database Syst Rev 2004;(4):CD001208.

38. Upadhyay M, Singhi S, Murlidharan J, et al. Randomized evaluation of fluid resuscitation with crystalloid (saline) and colloid (polymer from degraded gelatin in saline) in pediatric septic shock. Indian Pediatr 2005 ;42:223-31.

39. Vincent JL, Gerlach H. Fluid resuscitation in severe sepsis and septic shock: an evidence-based review. Crit Care Med 2004; 32:S451-4.
40. Brunkhorst FM, Engel C, Bloos F, et al. Intensive insulin therapy and pentastarch resuscitation in severe sepsis. N Engl J Med 2008;358:125-39.

41. Holmes CL. Vasoactive drugs in the intensive care unit. Curr Opin Crit Care 2005;11:413-7.

42. Holmes CL, Walley KR. The evaluation and management of shock. Clin Chest Med 2003;24:775-89.

43. Nguyen HB, Rivers EP, Abrahamian FM, et al. Emergency Department Sepsis Education Program and Strategies to Improve Survival (ED-SEPSIS) Working Group. Severe sepsis and septic shock: review of the literature and emergency department management guidelines. Ann Emerg Med 2006;48:28-54.

44. Dellinger RP, Carlet JM, Masur H, et al. Surviving sepsis campaign guidelines for management of severe sepsis and septic shock. Crit Care Med 2004;32:858-73.

45. Kuhl DA. Current strategies for managing the patient with sepsis. Am J Health Syst Pharm 2002;02/15(Suppl 1):S9-13.

46. Hollenberg SM, Ahrens TS, Annane D, et al. Practice parameters for hemodynamic support of sepsis in adult patients: 2004 update. Crit Care Med 2004;32:1928-48.

47. De Backer D, Creteur J, Silva E, et al. Effects of dopamine, norepinephrine, and epinephrine on the splanchnic circulation in septic shock: Which is best? Crit Care Med 2003;31:1659-67.

48. Martin C, Viviand X, Leone M, et al. Effect of norepinephrine on the outcome of septic shock. Crit Care Med 2000;28:2758-65.

49. Martin C, Papazian L, Perrin G, et al. Norepinephrine or dopamine for the treatment of hyperdynamic septic shock? Chest 1993;103:1826-31.

50. Marik PE, Mohedin M. The contrasting effects of dopamine and norepinephrine on systemic and splanchnic oxygen utilization in hyperdynamic sepsis. JAMA 1994;272:1354-7.

51. Redl-Wenzl EM, Armbruster C, Edelmann G, et al. The effects of norepinephrine on hemodynamics and renal function in severe septic shock states. Intensive Care Med 1993;19:151-4.

52. Levy B, Bollaert PE, Charpentier C, et al. Comparison of norepinephrine and dobutamine to epinephrine for hemodynamics, lactate metabolism, and gastric tonometric variables in septic shock: a prospective, randomized study. Intensive Care Med 1997;23:282-7.

53. Desjars P, Pinaud M, Potel G, et al. A reappraisal of norepinephrine therapy in human septic shock. Crit Care Med 1987; $15: 134-7$.

54. Meadows D, Edwards JD, Wilkins RG, et al. Reversal of intractable septic shock with norepinephrine therapy. Crit Care Med 1988;16:663-6.

55. Desjars P, Pinaud M, Bugnon D, et al. Norepinephrine therapy has no deleterious renal effects in human septic shock. Crit Care Med 1989;17:426-9.

56. Hesselvik JF, Brodin B. Low dose norepinephrine in patients with septic shock and oliguria: effects on afterload, urine flow, and oxygen transport. Crit Care Med 1989;17:179-80.

57. Marin C, Eon B, Saux P, et al. Renal effects of norepinephrine used to treat septic shock patients. Crit Care Med 1990;18:282-5.

58. Bellomo R, Chapman M, Finfer S, et al. Low-dose dopamine in patients with early renal dysfunction: a placebo-controlled randomised trial. Australian and New Zealand Intensive Care 
Society (ANZICS) Clinical Trials Group. Lancet 2000; 356:2139-43.

59. Kellum JA, Decker M. Use of dopamine in acute renal failure: a meta-analysis. Crit Care Med 2001;29:1526-31.

60. Olson D, Pohlman A, Hall JB. Administration of low-dose dopamine to nonoliguric patients with sepsis syndrome does not raise intramucosal gastric $\mathrm{pH}$ nor improve creatinine clearance. Am J Respir Crit Care Med 1996;154:1664-70.

61. Patel BM, Chittock DR, Russell JA, et al. Beneficial effects of short-term vasopressin infusion during severe septic shock. Anesthesiology 2002;96:576-82.

62. Malay MB, Ashton RC Jr, Landry DW, et al. Low-dose vasopressin in the treatment of vasodilatory septic shock. J Trauma 1999;47:699-703.

63. Holmes CL, Walley KR, Chittock DR, et al. The effects of vasopressin on hemodynamics and renal function in severe septic shock: a case series. Intensive Care Med 2001;27:1416-21.

64. Dufresne RG Jr. Skin necrosis from intravenously infused materials. Cutis 1987;39:197-8.

65. Greenwald RA, Rheingold OJ, Chiprut RO, et al. Local gangrene: a complication of peripheral pitressin therapy for bleeding esophageal varices. Gastroenterology 1978;74:744-6.

66. Kahn JM, Kress JP, Hall JB. Skin necrosis after extravasation of low-dose vasopressin administered for septic shock. Crit Care Med 2002;30:1899-901.

67. Korenberg RJ, Landau-Price D, Penneys NS. Vasopressininduced bullous disease and cutaneous necrosis. J Am Acad Dermatol 1986;15:393-8.

68. Rudis MI, Basha MA, Zarowitz BJ. Is it time to reposition vasopressors and inotropes in sepsis? Crit Care Med 1996;24: $525-37$.

69. Cohen J, Brun-Buisson C, Torres A, et al. Diagnosis of infection in sepsis: an evidence-based review. Crit Care Med 2004;32:S466-94.

70. Smith-Elekes S, Weinstein MP. Blood cultures. Infect Dis Clin North Am 1993;7:221-34.

71. Reimer LG, Wilson ML, Weinstein MP. Update on detection of bacteremia and fungemia. Clin Microbiol Rev 1997;10:444-65.

72. Wilson ML. General principles of specimen collection and transport. Clin Infect Dis 1996;22:766-77.

73. Broder G, Weil MH. Excess lactate: an index of reversibility of shock in human patients. Science 1964;143:1457-9.

74. Bernardin G, Pradier C, Tiger F, et al. Blood pressure and arterial lactate level are early indicators of short-term survival in human septic shock. Intensive Care Med 1996 ;22:17-25.

75. Shapiro NI, Howell MD, Talmor D, et al. Serum lactate as a predictor of mortality in emergency department patients with infection. Ann Emerg Med 2005;45:524-8.

76. Trzeciak S, Dellinger RP, Chansky ME, et al. Serum lactate as a predictor of mortality in patients with infection. Intensive Care Med 2007;33:970-7.

77. Aduen J, Bernstein WK, Khastgir T, et al. The use and clinical importance of a substrate-specific electrode for rapid determination of blood lactate concentrations. JAMA 1994;272: 1678-85.
78. Shapiro N, Howell MD, Bates DW, et al. The association of sepsis syndrome and organ dysfunction with mortality in emergency department patients with suspected infection. Ann Emerg Med 2006;48:583,90, 590.

79. Kumar A, Haery C, Paladugu B, et al. The duration of hypotension before the initiation of antibiotic treatment is a critical determinant of survival in a murine model of escherichia coli septic shock: association with serum lactate and inflammatory cytokine levels. J Infect Dis 2006;193:251-8.

80. Miner JR, Heegaard W, Mapes A, et al. Presentation, time to antibiotics, and mortality of patients with bacterial meningitis at an urban county medical center. J Emerg Med 2001;21:387-92.

81. Houck PM, Bratzler DW, Nsa W, et al. Timing of antibiotic administration and outcomes for medicare patients hospitalized with community-acquired pneumonia. Arch Intern Med 2004; 164:637-44.

82. Kumar A, Roberts D, Wood KE, et al. Duration of hypotension before initiation of effective antimicrobial therapy is the critical determinant of survival in human septic shock. Crit Care Med 2006;34:1589-96.

83. Bochud PY, Glauser MP, Calandra T. Antibiotics in sepsis. Intensive Care Med 2001;27(Suppl 1):S33-48.

84. Simon D, Trenholme G. Antibiotic selection for patients with septic shock. Crit Care Clin 2000;16:215-31.

85. Hughes WT, Armstrong D, Bodey GP, et al. 2002 guidelines for the use of antimicrobial agents in neutropenic patients with cancer. Clin Infect Dis $2002 ; 34: 730-51$.

86. Marshall JC, Maier RV, Jimenez M, et al. Source control in the management of severe sepsis and septic shock: an evidencebased review. Crit Care Med 2004;32:S513-26.

87. Moss RL, Musemeche CA, Kosloske AM. Necrotizing fasciitis in children: Prompt recognition and aggressive therapy improve survival. J Pediatr Surg 1996;31:1142-6.

88. Feistritzer C, Wiedermann CJ. Effects of anticoagulant strategies on activation of inflammation and coagulation. Expert Opin Biol Ther 2007;7:855-70.

89. Baillie JK. Activated protein C: Controversy and hope in the treatment of sepsis. Curr Opin Investig Drugs 2007;8:933-8.

90. Abraham E, Laterre PF, Garg R, et al. Drotrecogin alfa (activated) for adults with severe sepsis and a low risk of death N Engl J Med 2005 ;353:1332-41.

91. Bernard GR, Margolis BD, Shanies HM, et al. Extended Evaluation of Recombinant Human Activated Protein C United States Trial (ENHANCE US): a single-arm, phase 3B, multicenter study of drotrecogin alfa (activated) in severe sepsis. Chest 2004;125:2206-16.

92. Yildiz O, Doganay M, Aygen B, et al. Physiological-dose steroid therapy in sepsis [ISRCTN36253388]. Crit Care 2002;6:251-9.

93. Briegel J, Forst H, Haller M, et al. Stress doses of hydrocortisone reverse hyperdynamic septic shock: a prospective, randomized, double-blind, single-center study. Crit Care Med 1999;27:723-32.

94. Bollaert PE, Charpentier C, Levy B, et al. Reversal of late septic shock with supraphysiologic doses of hydrocortisone. Crit Care Med 1998;26:645-50. 
95. Keh D, Boehnke T, Weber-Cartens S, et al. Immunologic and hemodynamic effects of "low-dose" hydrocortisone in septic shock: a double-blind, randomized, placebo-controlled, crossover study. Am J Respir Crit Care Med 2003 02/15;167(4):512-20.

96. Minneci PC, Deans KJ, Banks SM, et al. Meta-analysis: the effect of steroids on survival and shock during sepsis depends on the dose. Ann Intern Med 2004;141:47-56.

97. Annane D, Bellissant E, Bollaert PE, et al. Corticosteroids for severe sepsis and septic shock: a systematic review and metaanalysis. BMJ 2004;329:480.

98. Annane D, Sebille V, Troche G, et al. A 3-level prognostic classification in septic shock based on cortisol levels and cortisol response to corticotropin. JAMA 2000;283:1038-45.

99. Sprung CL, Annane D, Keh D, et al. Hydrocortisone therapy for patients with septic shock. N Engl J Med 2008;358:111-24.

100. Marik PE, Zaloga GP. Adrenal insufficiency during septic shock. Crit Care Med 2003;31:141-5.

101. Bourne RS, Webber SJ, Hutchinson SP. Adrenal axis testing and corticosteroid replacement therapy in septic shock patientslocal and national perspectives. Anaesthesia 2003;58:591-6.

102. Bouachour G, Tirot P, Gouello JP, et al. Adrenocortical function during septic shock. Intensive Care Med 1995;21:57-62.

103. Rothwell PM, Udwadia ZF, Lawler PG. Cortisol response to corticotropin and survival in septic shock. Lancet 1991;337: $582-3$.

104. Goodman S, Sprung CL, Ziegler D, et al. Cortisol changes among patients with septic shock and the relationship to ICU and hospital stay. Intensive Care Med 2005;31:1362-9.

105. Keh D, Sprung CL. Use of corticosteroid therapy in patients with sepsis and septic shock: an evidence-based review. Crit Care Med 2004;32:S527-33.

106. Hebert PC, Wells G, Blajchman MA, et al. A multicenter, randomized, controlled clinical trial of transfusion requirements in critical care. transfusion requirements in critical care investigators, canadian critical care trials group. N Engl J Med 1999; 340:409-17.

107. Fan E, Needham DM, Stewart TE. Ventilatory management of acute lung injury and acute respiratory distress syndrome. JAMA 2005;294:2889-96.

108. Kallet RH. Evidence-based management of acute lung injury and acute respiratory distress syndrome. Respir Care 2004;49: 793-809.

109. Ventilation with lower tidal volumes as compared with tradi- tional tidal volumes for acute lung injury and the acute respiratory distress syndrome. The acute respiratory distress syndrome network. N Engl J Med 2000;342:1301-8.

110. Kollef MH, Schuster DP. The acute respiratory distress syndrome. N Engl J Med 1995;332:27-37.

111. Bernard GR, Artigas A, Brigham KL, et al. The AmericanEuropean consensus conference on ARDS. Definitions, mechanisms, relevant outcomes, and clinical trial coordination. Am J Respir Crit Care Med 1994;149:818-24.

112. Hickling KG, Walsh J, Henderson S, et al. Low mortality rate in adult respiratory distress syndrome using low-volume, pressurelimited ventilation with permissive hypercapnia: a prospective study. Crit Care Med 1994;22:1568-78.

113. Amato MB, Barbas CS, Medeiros DM, et al. Effect of a protective-ventilation strategy on mortality in the acute respiratory distress syndrome. N Engl J Med 1998;338:347-54.

114. Stewart TE, Meade MO, Cook DJ, et al. Evaluation of a ventilation strategy to prevent barotrauma in patients at high risk for acute respiratory distress syndrome. pressure- and volume-limited ventilation strategy group. N Engl J Med 1998;338:355-61.

115. Bidani A, Tzouanakis AE, Cardenas VJ Jr, et al. Permissive hypercapnia in acute respiratory failure. JAMA 1994;272:957-62.

116. Stocker R, Neff T, Stein S, et al. Prone positioning and lowvolume pressure-limited ventilation improve survival in patients with severe ARDS. Chest 1997;111:1008-17.

117. Jolliet P, Bulpa P, Chevrolet JC. Effects of the prone position on gas exchange and hemodynamics in severe acute respiratory distress syndrome. Crit Care Med 1998;26:1977-85.

118. Gattinoni L, Tognoni G, Pesenti A, et al. Effect of prone positioning on the survival of patients with acute respiratory failure. N Engl J Med 2001;345:568-73.

119. Papazian L, Gainnier M, Marin V, et al. Comparison of prone positioning and high-frequency oscillatory ventilation in patients with acute respiratory distress syndrome. Crit Care Med 2005;33:2162-71.

120. Van den Berghe G, Wilmer A, Hermans G, et al. Intensive insulin therapy in the medical ICU. N Engl J Med 2006;354:449-61.

121. Malhotra A. Intensive insulin in intensive care. N Engl J Med 2006;354:516-8.

Correspondence: Dr. Robert S. Green, Chair, CAEP Critical Care Interest Group; 1278 Tower Rd., Rm. 349, Bethune Bldg., Halifax NS B3H 2Y9; greenrs@dal.ca 